\author{
Mehmet Akif Ersoy Üniversitesi Fen Bilimleri Enstitüsü Dergisi 12(1): 69-75 (2021) \\ The Journal of Graduate School of Natural and Applied Sciences of Mehmet Akif Ersoy University 12(1): 69-75 (2021)
}

Araştırma Makalesi / Research Paper

\title{
COVID-19 Pandemi Sürecinde Parklar Üzerine Kullanıcıların Görüşleri: Antalya-Konyaaltı Örneği
}

\author{
Ayşe SARP $\mathbb{D}^{1}$, Cengiz YÜCEDAĞ ${ }^{\mathbb{D}} 2^{*}$, Latif Gürkan KAYA $\mathbb{D}_{2}$ \\ ${ }^{1}$ Burdur Mehmet Akif Ersoy Üniversitesi, Fen Bilimleri Enstitüsü, Burdur \\ ${ }^{2}$ Burdur Mehmet Akif Ersoy Üniversitesi, Mühendislik Mimarlık Fakültesi, Burdur \\ Geliş Tarihi (Received): 09.02.2021, Kabul Tarihi (Accepted): 14.03.2021 \\ $\square$ Sorumlu Yazar (Corresponding author $\left.{ }^{\star}\right):$ yucedagc@gmail.com

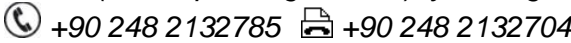

ÖZ

COVID-19 pandemisi, bir yılı aşkın süredir tüm dünya üzerinde etkisini göstermiştir. Hala devam etmekte olan pandeminin yayılımını azaltmak için ülkeler ve kentler farklı tedbirler ve kısıtlamalar uygulamaktadır. Kısıtlamalarla kapalı hizmet alanları kullanıma kapatıldıkça parklar insanlar tarafından güvenli sosyalleşme ortamı olarak seçilmektedir. Bu çalışmanın amaçları, Antalya ili Konyaaltı ilçesinde ikamet eden insanların pandemi sürecinde parklar üzerine görüşlerini ortaya koymak ve parklar üzerine katıımcıların görüşlerine etkili olan faktörleri belirlemektir. Çalışmada, katılımcıların çoğunluğunun pandemi sürecinde parkları ziyaret ettiği ve ilk ziyaret amaçlarının yürüyüş yapmak olduğu tespit edilmiştir. Katıımcıların çoğu, pandemi sürecinde parkların kullanımının arttığını, pandemi sürecinde parkların kullanıcılara doğada/açık yeşil alanda zaman geçirme fırsatı sunduğunu ve pandemi sürecinde ortaya çıkan ihtiyaçlar doğrultusunda parkların plan ve tasarımlarının geliştirilerek kullanım devamlııklarının sağlanması gerektiğini düşünmektedir. Cinsiyet, medeni durum, yaş, meslek, gelir düzeyi ve COVID-19 testinin pozitif çıkma durumu pandemi sürecinde parklar üzerine katılımcıların farklı görüşlerine etkili bulunmuştur. Buna karşılık, katılımcıların eğitim durumları ile kronik bir hastalığa sahip olup olmamaları, pandemi sürecinde parklar üzerine katılımcıların görüşlerine etkili bulunmamıştır. Sonuç olarak, parkların planlama ve tasarımlarının daha kapsamlı yapılmasının ileride yaşanabilecek pandemi süreçlerinde kullanıcılara daha kaliteli hizmet sunmalarına katkı sağlayacağı unutulmamalıdır.

Anahtar Kelimeler: Antalya, COVID-19 pandemisi, Konyaaltı, park kullanımı

\section{Views of Users on Parks during COVID-19 Pandemic: The Case Study of Antalya-Konyaaltı, Turkey}

\section{ABSTRACT}

The COVID-19 pandemic has had an impact on the entire world for more than one year. Countries and cities have carried out different measures and restrictions to reduce the spread of the pandemic that is still ongoing. Parks have been preferred as a safe socialization environment by people as indoor service areas are closed after restrictions. The aims of this study are to reveal the views of visitors on the parks during the pandemic residing in Antalya-Konyaaltı and to determine the factors that influence the views of the visitors. In the study, it was determined that the majority of the participants visited the parks during the pandemic and the first purpose of their visit was to take a walk. Most of the volunteers thought that the use of parks has increased during the pandemic, that the parks offer the visitors the opportunity to spend time in nature/open green land during the pandemic, and that the plan and designs of the park areas should be improved considering the needs that arise during the pandemic and thus their use continuity should be ensured. Gender, marital status, age, job, income level and If the COVID-19 test is positive were found to be effective on the different views of the participants on parks during the pandemic but the educational status of the participants and if they have a chronic disease were not found to be effective. As a result, it should not be forgotten 
COVID-19 Pandemi Sürecinde Parklar Üzerine Kullanıcıların Görüşleri: Antalya-Konyaaltı Örneği

that the planning and design of the parks will contribute to providing better quality service to the users in the pandemic processes that may occur in the future.

Keywords: Antalya, COVID-19 pandemic, Konyaaltı, park use

\section{GíRiş}

COVID-19 hastalığı, Aralık 2019'da Çin'in Hubei eyaleti Wuhan kentinden başlayarak, dünya genelini etkisi altına almış (Üstün ve Özçiftçi, 2020) ve Dünya Sağlık Örgütü (WHO) tarafından 11 Mart 2020 tarihinde pandemi olarak kabul edilmiştir (Altın, 2020; Yücedağ ve Çetin, 2020). Bu pandemi ile beraber dünya çapında insan yaşamının çeşitli yönleri, kuralları ve rutinleri değişmeye başlamıştır (Zhao, 2020). Pandeminin etkisini azaltmak ve yayılımını yavaşlatmak için tüm dünyada farklı sürelerde sokağa çıkma yasakları, karantina ve izolasyon süreçleri ve sosyal mesafenin korunması gibi tedbirler alınmaktadır (Bozkurt, 2020). Kentsel tedbirler kapsamında insanların gezi alanları sınırlı hale gelmektedir. Pandemi sürecinin kısıtlamaları içerisinde kentte yer alan açık hava parkları insanların sosyalleşmesi konusunda yardımcı olabilmekte, fiziksel ve ruhsal açıdan rahatlama intiyaçlarını giderebilmek için farklı açık hava etkinlikleri (piknik vb.) ve spor aktiviteleri için fırsat sağlamaktadır (Xie ve ark., 2020).

Pandeminin ortaya çıkmasından sonra düzenli yapılan günlük egzersiz ve aktivitelerin aksamasına rağmen (Chen ve ark., 2020), aslında bu dönemde normal zamanda olduğu gibi yapılan rekreasyon faaliyetleri bireylerin mutlu ve sağlıklı olmasını ve moralinin yükselmesini sağlayabilir. Fazlaca evde kalan tüm bireyler fiziksel aktivitelerini gerçekleştirmek için yakın çevrelerindeki alanları kullanmaktadır (Güzel ve ark., 2020). Bu anlamda; TPL Special Report (2020)'e göre; karan- tina sürelerinde kapalı ve toplu alanlar (sinema salonları, restoranlar vb.) kullanıma kapatıldıkça parklar güvenli alan olarak ortaya çıkmaktadır. Buna bağlı olarak çoğu ülke ve kentler kısıtlama süreçlerinde parkları açık tutarak insanlara gezi ve sosyalleşme alanı yaratmaktadır. Parkların ve kamu arazilerinin süreç içinde en yüksek kullanıma ulaştığı ve ziyaretçi sayısında ciddi artış olduğu bu raporda bildirilmektedir. Pandemi sürecinde park ziyaretlerinin, farklı ülkelerde başlarda azalma ve artışta değişkenlik gösterirken, sonrasında ise yüksek seviyelere çıktığı belirtilmektedir. Bunun sebebinin, devam etmekte olan izolasyonlardan sıkılan insanların parkların sağlıklı açık hava rekreasyonu açısından önemli işlevlere ve fırsatlara sahip olduğunun farkına varmasıyla ortaya çıktığı düşünülmektedir (Geng ve ark., 2020).

Yukarıda verilen bilgiler doğrultusunda bu çalışmada, araştırma alanı olarak belirlenen Antalya ili Konyaaltı ilçesinde ikamet eden insanların pandemi sürecinde parkların durumu üzerine görüşlerini ortaya koymak ve parklar üzerine katılımcıların görüşlerine etkili olan faktörleri belirlemek amaçlanmıştır.

\section{MATERYAL VE YÖNTEM}

Çalışma alanı olarak Antalya ili, Konyaaltı ilçesi seçilmiştir (Şekil 1). TÜİK (2020) verilerine göre, Antalya ili nüfusu 2.548.308, Konyaaltı ilçe nüfusu ise 189.078'tür.

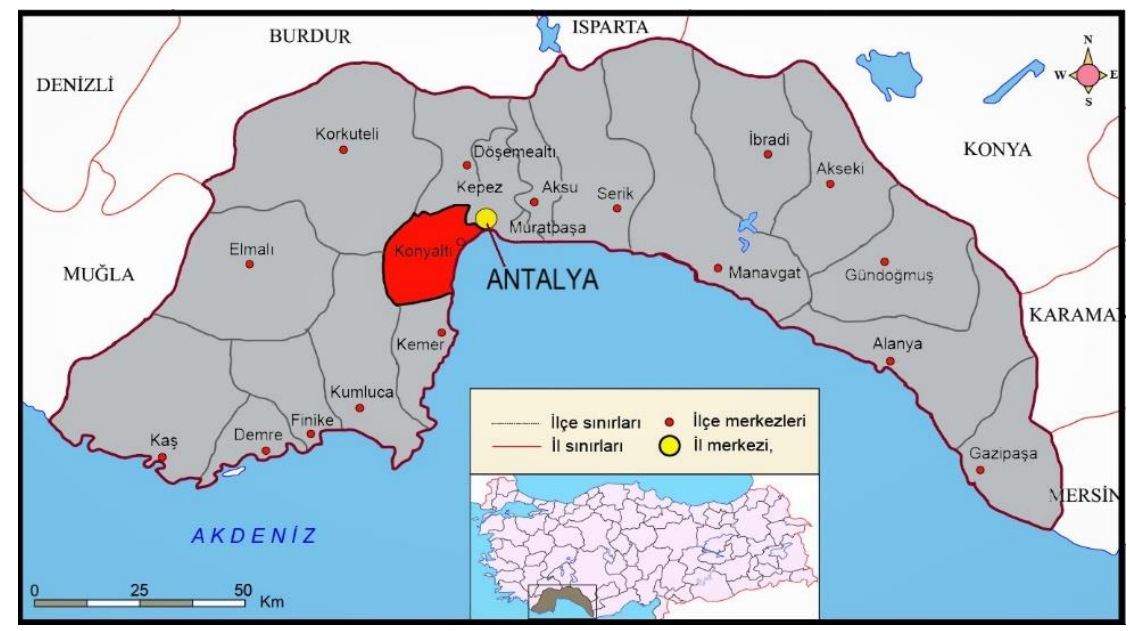

Şekil 1. Çalışma alanının konumu 
COVID-19 Pandemi Sürecinde Parklar Üzerine Kullanıcıların Görüşleri: Antalya-Konyaaltı Örneği

Çalışmada veri toplama için anket yöntemi uygulanmıştır. Anket formunun geliştirilmesinde Rice ve ark., (2020) ile Rice ve Pan (2020)'in çalışmalarından da yararlanılmıştır. Anket araştırmanın amacına uygun ve yeterli veriye ulaşılabilmek için dört bölümden oluşmakta ve ankette toplam 23 soru yer almaktadır. Birinci bölümdeki 6 soru katılımcıların demografik özelliklerine yönelik sorulardır. İkinci bölümdeki 3 soru katılımcıların kronik rahatsızlığı ve COVID-19 olma durumlarına ilişkin sorulardır. Üçüncü bölüm, park ziyaretlerine ilişkin 2 soruyu içermektedir. Ankette 11 maddeden oluşan dördüncü bölüm için üçlü Likert ölçeği kullanılmıştır. Anket uygulaması, 2020 yılının Aralık ayında Antalya ili Konyaaltı ilçesinde toplam 260 katılımcıya Google Docs Programı üzerinden hazırlanan formla çevrimiçi olarak uygulanmıştır. Çalışmada, dördüncü bölümdeki 11 maddenin güvenirliğinin iç tutarlık analizinde Cronbach alfa değeri 0,72 olarak bulunmuştur. Çalışma kapsamında frekans analizi, ttesti ve tek yönlü varyans analizleri gerçekleştirilmiştir. Varyans analizi ile ortalamaları arasında önemli farklılık olduğu tespit edilen grupların benzer ya da farklı olanlarını bulmak amacıyla da çoklu karşılaştırmalı testlerden Duncan testi uygulanmıştır. Araştırma analizleri SPSS istatistik programı ile yapılmıştır.

\section{BULGULAR VE TARTIŞMA}

Anket katılımcılarının \%59,6'sının kadın, \%40,4'ünün erkek, \%61,9'unun evli, \%38,1'inin bekar olduğu tespit edilmiştir. Katılımcıların \%65'i 26-45 yaş aralığında dağılım gösterirken, $\% 73,1$ 'i önlisans ve lisans mezunudur. Çoğunluğu $(\% 74,8) 5001$ TL ve üstü aylık gelire sahip olan katılımcıların yaklaşık yarısı $(\% 48,1)$ diğer meslek çalışanlarından oluşmaktadır. Ankete katılanlara kronik rahatsızlığa sahip olma durumu sorulduğunda, \%15'i evet, \%85'i ise hayır cevabını vermiştir (Tablo 1). Bu çaIışmada elde edilen bulguya benzer şekilde, Güngör ve Öner (2020) tarafından yapılan çalışmada da katılımcıların \%86'sı kronik rahatsızlığı olmadığını belirtmiştir.

Tablo 1. Katılımcıların demografik özelliklerine ilişkin frekans ve yüzde (\%) dağılımları

\begin{tabular}{|c|c|c|c|c|c|}
\hline Özellikler & $f$ & $\%$ & Özellikler & $f$ & $\%$ \\
\hline \multicolumn{3}{|l|}{ Cinsiyet } & \multicolumn{3}{|c|}{ Medeni Durum } \\
\hline Kadın & 155 & 59,6 & Evli & 161 & 61,9 \\
\hline Erkek & 105 & 40,4 & Bekar & 99 & 38,1 \\
\hline \multicolumn{3}{|l|}{ Yaş } & \multicolumn{3}{|l|}{ Eğitim } \\
\hline $18-25$ & 36 & 13,8 & İlkokul & 6 & 2,3 \\
\hline $26-35$ & 108 & 41,5 & Ortaokul & 2 & 0,8 \\
\hline $36-45$ & 61 & 23,5 & Lise & 41 & 15,7 \\
\hline $46-55$ & 29 & 11,2 & Ön Lisans & 48 & 18,5 \\
\hline $56-65$ & 21 & 8,1 & Lisans & 142 & 54,6 \\
\hline 66 yaş üstü & 5 & 1,9 & Lisansüstü & 21 & 8,1 \\
\hline \multicolumn{3}{|l|}{ Meslek } & \multicolumn{3}{|c|}{ Gelir Düzeyi (TL) } \\
\hline Öğrenci & 26 & 10,0 & 2500 ve altı & 67 & 25,8 \\
\hline Memur & 31 & 11,9 & $2501-5000$ & 105 & 40,4 \\
\hline İşçi & 21 & 8,1 & $5001-7500$ & 56 & 21,5 \\
\hline Ev hanımı & 29 & 11,1 & 7501 ve üstü & 32 & 12,3 \\
\hline Emekli & 28 & 10,8 & \multicolumn{3}{|c|}{ Kronik rahatsızlığa sahip olma durumu } \\
\hline \multirow{2}{*}{ Diğer } & \multirow{2}{*}{125} & \multirow{2}{*}{48,1} & Evet & 39 & 15,0 \\
\hline & & & Hayır & 221 & 85,0 \\
\hline
\end{tabular}

Katılımcıların çoğunluğu COVID-19 testi yaptırmadığını $(f=163$ ) ve temaslı olmadığını ( $f=211$ ) belirtmiştir (Şekil 2). 
COVID-19 Pandemi Sürecinde Parklar Üzerine Kullanıcıların Görüşleri: Antalya-Konyaaltı Örneği

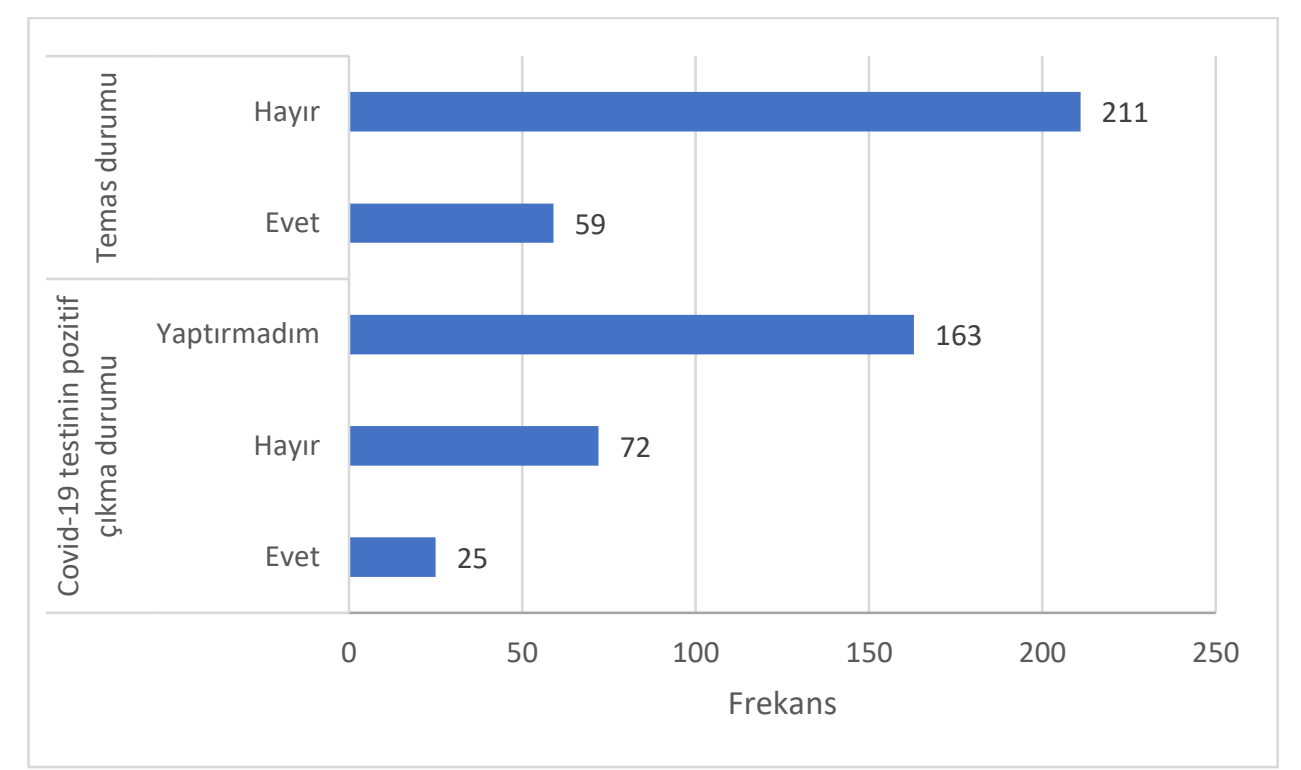

Şekil 2. Katılımcıların COVID-19 testinin pozitif çıkma ve temaslı olma durumları $(n=260)$

Katılımcıların çoğunluğu ( $f=193$ ) pandemi sürecinde parkları ziyaret ettiklerini ifade etmişlerdir (Şekil 3). Johnson ve ark. (2020) tarafından tamamlanan bir çaIışma mağaza ve işyeri ziyareti gibi yapılan aktivitelerden daha ziyade yeşil alanların kullanımının COVID-19 hastalığının yayılım oranını azaltabildiğini işaret etmiştir. Bir başka araştırmada (Güngör ve Öner, 2020) ise, COVID-19 sürecinde insanların \%82'sinin haftada en bir kez açık havaya çıktıkları sonucuna ulaşılmıştır. Buna karşılık, Rice ve ark. (2020) tarafından kentsel alanlardaki insanlar arasında dış mekan rekreasyonel aktiviteye katııım sayısının önemli ölçüde azaldığını belirtmişlerdir. Diğer taraftan, Landry ve ark. (2020) tarafından insanların COVID-19 sürecinde dış mekan rekreasyonel alanlarını ziyaret ettikleri ancak ziyaret kalitelerinin COVID-19 risk ve sınırlamalarından dolayı azaldığı vurgulanmıştır. Xie ve ark. (2020) pandemi sürecinde insanların parkları ziyaret sayısının düşmesine rağmen, haftada bir bile olsa parkları ziyaret etmelerinin yararlı olabileceğini önermişlerdir.

Parkları ziyaret eden katılımcıların büyük çoğunluğu parkları yürüyüş yapmak ( $f=97)$ amaçlı kullanmışlardır (Şekil 3). Görüldüğü üzere, katılımcılar tarafından parklar spor amaçlı çok kullanılmamış olmasına rağmen, spor yapmak aslında COVID-19 hastalığının yayılımını yavaşlatmada pozitif bir katkı sunmaktadır (Parnell ve ark., 2020).

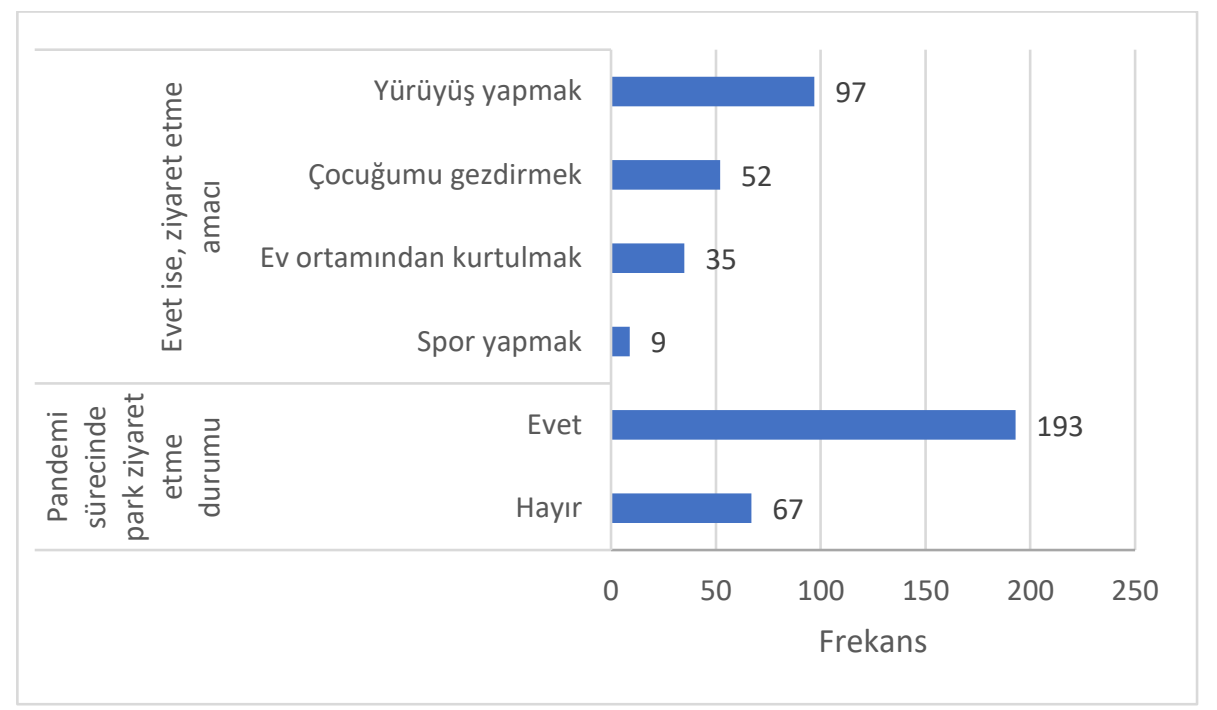

Şekil 3. Katılımcıların pandemi sürecinde park ziyaret etme durumları $(n=260)$ ile ziyaret etme amaçları $(n=193)$ 
COVID-19 Pandemi Sürecinde Parklar Üzerine Kullanıcıların Görüşleri: Antalya-Konyaaltı Örneği

Katılımcıların çoğunluğu pandemi sürecinde parkların kullanımının arttığı $(f=120)$, pandemi sürecinde parkların kullanıcılara doğada/açık yeşil alanda zaman geçirme fırsatı sunduğu $(f=162)$ ve pandemi sürecinde ortaya çıkan ihtiyaçlar doğrultusunda (geniş ölçekli parklar, mesafeli oturma alanları, yürüyüş parkurları vb.) park alanlarının plan ve tasarımlarının geliştirilerek kullanım devamlılıklarının sağlanması gerektiği $(f=191)$ konularında "katılıyorum" seçeneğini belirtmişlerdir. Pandemi sürecinde parkların kullanıma ilişkin yöneltilen diğer maddelere katılımcıların çoğunluğu orta düzeyde katıımışlardır (Tablo 2). Pandemi sürecinde parkların ve yeşil alanların kapatılması sağlıklı dış mekan aktivitesi ve stres azaltma olanaklarını sınırlar ve bireyleri daha az uygun ve daha fazla sıkışık mekanlara yönlendirebilir. Aslında, güvenli park kullanımını ve dış mekan rekreasyonunu düzenlemek için alınması gerekli önlemleri erkenden benimseme ciddi bir husustur ve bir halk sağlığı önceliği olmaIıdır (Cortinez-O'Ryan ve ark., 2020). Bu anlamda,
COVID-19 hastalığının potansiyel toplumsal yayılma riskine karşı dış mekan rekreasyonel alanlarının yönetimi insanların intiyaçlarını karşılamak için dikkatli bir analizi gerektirir (Freeman ve Eykelbosh, 2020). İleride planlamacı ve peyzaj mimarlarının pandemi dönemleri için parkların fonksiyonlarını düşünmeleri gerekmektedir (Xie ve ark., 2020).

Bu çalışmada katılımcılar "Pandemi sürecinde parklar kullanıcıların sosyalleşebilmesi için güvenilir alanlar olmuştur." maddesi için orta düzeyde katıldıklarını (Tablo 2) belirtmelerine rağmen, Xie ve ark. (2020) tarafından tamamlanan araştırma pandemi sürecinde parkların insanlara güvenli dış mekan aktivitesi ve sosyal etkileşim için bir yer sağlayabildiğini ortaya koymuştur. Aynı araştırmacılar, parkların sağlık ve hayat kalitesini sürdürmek için bir tampon alan görevi gördüklerini de belirtmişlerdir.

Tablo 2. Katılımcıların pandemi sürecinde parklar üzerine kullanıcıların görüşleri

\begin{tabular}{|c|c|c|c|}
\hline \multirow[b]{2}{*}{ Maddeler } & 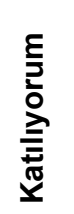 & 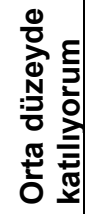 & غ \\
\hline & \multicolumn{3}{|c|}{ Frekans } \\
\hline 1. Pandemi sürecinde parkların kullanımı artmıştır. & 120 & 83 & 57 \\
\hline 2. Pandemi sürecinde parklarda kullanıcılar tedbirlere (maske, mesafe, vb.) uymaktadır. & 52 & 150 & 58 \\
\hline 3. Pandemi sürecinde parklar kullanıcıların sosyalleşebilmesi için güvenilir alanlar olmuştur. & 44 & 124 & 92 \\
\hline 4. Pandemi sürecinde parklar kullanıcıları fiziksel aktiviteye teşvik etmektedir. & 98 & 103 & 59 \\
\hline $\begin{array}{l}\text { 5. Pandemi sürecinde parklar kullanıcılara doğada/açık yeşil alanda zaman geçirme fırsatı } \\
\text { sunmaktadır. }\end{array}$ & 162 & 73 & 25 \\
\hline $\begin{array}{l}\text { 6. Pandemi sürecinde parklardaki oturma elemanları kullanıcılar için mesafeli kullanıma uy- } \\
\text { gundur. }\end{array}$ & 76 & 122 & 62 \\
\hline 7. Pandemi sürecinde parkların rekreasyon alanları kullanıcılar için yeterlidir. & 47 & 129 & 84 \\
\hline $\begin{array}{l}\text { 8. Pandemi sürecinde parkları akşam saatinde tercih eden kullanıcılar için aydınlatmaları } \\
\text { yeterlidir. }\end{array}$ & 75 & 111 & 74 \\
\hline $\begin{array}{l}\text { 9. Pandemi sürecinde parklardaki donatılar (çöp kovası, oturma birimleri vb.) kullanıcılar } \\
\text { için yeterlidir. }\end{array}$ & 75 & 118 & 67 \\
\hline 10. Pandemi sürecinde parkların temizliği yeterlidir. & 73 & 118 & 69 \\
\hline $\begin{array}{l}\text { 11. Pandemi sürecinde ortaya çıkan ihtiyaçlar doğrultusunda (geniş ölçekli parklar, mesafeli } \\
\text { oturma alanları, yürüyüş parkurları vb.) park alanlarının plan ve tasarımlarının geliştirile- } \\
\text { rek kullanım devamlılığı sağlanmalıdır. }\end{array}$ & 191 & 51 & 18 \\
\hline
\end{tabular}

Cinsiyetin sadece "Pandemi sürecinde parkların temizliği yeterlidir." maddesi üzerine etkili olduğu belirlenmiştir (tcinsiyet $=0,538 ; p=0,000$ ). Buna göre, erkekler kadınlara kıyasla parkların temizliğini daha yeterli bulmaktadırlar.
Medeni durum "Pandemi sürecinde parkların kullanımı artmıştır." (tmedeni durum=2,139; $p=0,034$ ) ve "Pandemi sürecinde parklar kullanıcıları fiziksel aktiviteye teşvik etmektedir." (tmedeni durum $=2,387 ; p=0,018$ ) maddeleri üzerine etkili bulunmuştur. Bekar katılımcılar evlilere kıyasla bu maddelere daha fazla katılmaktadırlar. Bu bulguya 
paralel şekilde, Cortinez-O'Ryan ve ark. (2020) parkların obezite, hipertansiyon ve kalp hastalıkları gibi kronik rahatsızlıkları engelleyerek ve kontrol ederek COVID-19'a direnci artırabilen fiziksel aktiviteye olanaklar sağladığını belirtmişlerdir.

Yaşın sadece "Pandemi sürecinde parkların kullanımı artmıştır." maddesi üzerine etkili olduğu ortaya çıkmıştır $\left(F_{\text {yaş }}=2,424 ; p=0,036\right)$. Buna göre, $18-35$ yaş arası ve 66 ve üstü yaşa sahip katılımcılar diğer yaş grubundaki katılımcılara kıyasla pandemi sürecinde parkların kullanımının arttığını daha fazla düşünmektedirler.

Mesleğin sadece "Pandemi sürecinde parklarda kullanıcllar tedbirlere (maske, mesafe, vb.) uymaktadır." mad-

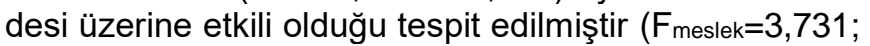
$p=0,003$ ). Buna göre, ev hanımı ve emekliler diğer meslek sahibi katılımcılara kıyasla bu konuya daha fazla katılmışlardır.

Gelir düzeyi ( $\left.F_{\text {gelir düzeyi }=5,661 ;} p=0,001\right)$ ve COVID-19 testinin pozitif çıkma durumu (F $p=0,020$ ) bağımsız değişkenlerinin sadece "Pandemi sürecinde parklardaki oturma elemanları kullanıcılar için mesafeli kullanıma uygundur." maddesi üzerine etkili oldukları ortaya çıkmıştır. 2501-7500 TL gelire sahip ve COVID-19 testi pozitif olan katılımcılar diğer katılımcllara kıyasla parklardaki oturma elemanlarının mesafeli kullanıma uygun olduğuna daha fazla katılmışlardır.

Katıımcıların eğitim durumları ile kronik bir hastalığa sahip olup olmamaları, pandemi sürecinde parklar üzerine katılımcıların görüşlerine etkili bulunmamıştır $(p>0,05)$.

\section{SONUÇLAR}

Bu araştırmada, tüm dünyayı etkisi altın alan COVID-19 pandemi sürecinde park kullanımının arttığı, tedbir ve kısıtlamalardan sıkılan insanların farklı rekreasyonel ve sosyal faaliyetler için parkları tercih ettiği sonucuna ulaşılmıştır. Bu süreçte parkları kullanan insanların ev ortamından kurtulmak, spor yapmak, yürüyüş yapmak veya çocuklarını gezdirmek amacıyla parkları ziyaret ettikleri anlaşılmıştır. Pandemi sürecinde ortaya çıkan ihtiyaçlar doğrultusunda geniş ölçekli parklar ve bu parklar içerisinde mesafeli oturma birimleri, yürüyüş parkurları vb. gibi park alanlarının plan ve tasarımlarının geliştirilerek kullanım devamlıığının sağlanması hususu önem kazanmıştır. Kapalı ve toplu hizmet veren yerlerin pandemiden dolayı kapatılması ile beraber sosyalleşmek için açık hava parklarına yönelen kullanıcılar bu süreçte doğada ve açık yeşil alanda zaman geçirme fırsatı bulmuştur.
Sonuç olarak; pandemi sürecinde yeniden önem kazanan parkların kullanım devamlıı̆ı için tasarım ve planlamalarının daha kapsamlı yapılmasının ileride yaşanabilecek pandemi süreçlerinde kullanıcılara daha kaliteli hizmet sunmalarına katkı sağlayacağı unutulmamalıdır.

\section{KAYNAKLAR}

Altın, Z. (2020). Covid-19 pandemisinde yaşlılar. Tepecik Eğitim ve Araştırma Hastanesi Dergisi, 30(Ek sayı): 49-57.

Bozkurt, A. (2020). Koronavirüs (COVID-19) pandemi süreci ve pandemi sonrası dünyada eğitime yönelik değerlendirmeler: Yeni normal ve yeni eğitim paradigması. Açıköğretim Uygulamaları ve Araştırmaları Dergisi. 6(3): 112-142.

Chen, P., Mao, L., Nassis, G.P., Harmer, P., Ainsworth, B.E., $\mathrm{Li}, \mathrm{F} .(2020)$. Coronavirus disease (COVID-19): The need to maintain regular physical activity while taking precautions. Journal of Sport and Health Science, 9: 103-104.

Cortinez-O'Ryan, A., Moran, M.R., Rios, A.P., Anza-Ramirez, C., Slovic, A.D. (2020). Could severe mobility and park use restrictions during the COVID-19 pandemic aggravate health inequalities? Insights and challenges from Latin America. Cadernos De Saúde Pública, 36(9):e00185820.

Freeman, S., Eykelbosh, A. (2020). COVID-19 and outdoor safety: Considerations for use of outdoor recreational spaces. Vancouver, BC: National Collaborating Centre for Environmental Health. 2020 April.

Geng, D., Innes, J., Wu, W., Wang, G. (2020). Impacts os COVID-19 pandemic on urban park visitation: a global analysis. Journal of Forestry Research, 32: 553-567.

Güngör, S., Öner, B. (2020). The Change in recreational activity usage in the normalization process after Covid-19 and Individuals' cravings for urban green areas. Turkish Journal of Agriculture - Food Science and Technology, 8(sp1): 812.

Güzel, P., Yıldız, K., Esentaş, M., Zerengök, D. (2020). “KnowHow" to spend time in home isolation during COVID-19; restrictions and recreational activities. International Journal of Psychology and Educational Studies, 7(2), 122-131.

Johnson, T.F., Hordley, L.A., Greenwell, M.P., Evans, L.C. (2020). Effect 1 of park use and landscape structure on COVID-19 transmission rates. doi: https://doi.org/10.1101/2020.10.20.20215731.

Landry, C.E., Bergstrom, J., Salazar, J., Turner, D. (2020). How has the COVID-19 pandemic affected outdoor recreation in the USA? Revealed Preference Approach. Applied Economic Perspectives and Policy, doi:10.1002/aepp.13119.

Parnell, D., Widdop, P., Bond, A., Wilson, R. (2020): COVID19, networks and sport, Managing Sport and Leisure, doi: 10.1080/23750472.2020.1750100.

Rice, W.L., Mateer, T.J., Reigner, N., Newman, P., Lawhon, B., Taff, B.D. (2020). Changes in recreational behaviors of outdoor enthusiasts during the COVID-19 pandemic: analysis across urban and rural communities. Journal of Urban Ecology, doi: 10.1093/jue/juaa020.

Rice, W., Pan, B. (2020). Understanding drivers of change in park visitation during the COVID-19 pandemic: A spatial 
application of Big data. Pennsylvania State University, Department of Recreation, Park and Tourism Management, doi:10.31235/osf.io/97qa4.

TPL Special Report (2020). Parks and the pandemic. A trust for public land special report. 1-12. https://www.tpl.org/sites/default/files/Parks\%20and\%20Pandemic\%20-

\%20TPL\%20special\%20 report.pdf (Erişim Tarihi: 22.12.2020).

TÜíK (2020). Adrese dayalı nüfus kayıt sistemi. https://biruni.tuik.gov.tr/medas/?kn=95\&amp;locale=tr (Erişim Tarihi: 09.02.2021).
Üstün, Ç., Özçiftçi, S. (2020). COVID-19 pandemisinin sosyal yaşam ve etik düzlem üzerine etkileri: bir değerlendirme çaıışması. Anadolu Kliniği Tıp Bilimleri Dergisi. 25: 142-153.

Xie, J., Luo, S., Furuya, K., Sun, D. (2020). Urban parks as green buffers during the COVID-19 pandemic. Sustainability. 12: 1-17.

Yücedağ, C., Çetin, M. (2020). Identifying leisure perceptions and activities of EFL teachers in home Isolation during the COVID-19 pandemic. Kastamonu University Journal of Engineering and Sciences, 6(2): 62-72.

Zhao, Y. (2020). COVID-19 as a catalyst for educational change. Prospects, 49: 29-33. 